\title{
Tryptic Peptide Signal Enhancement via MALDI IMS Post-ionization (MALDI-2) from Thin Tissue Sections
}

\author{
Josiah C. McMillen ${ }^{1,2}$, Danielle B. Gutierrez ${ }^{2,3}$, Audra M. Judd ${ }^{2}$, Jeffrey M. Spraggins ${ }^{1,2,3 *}$, and Richard \\ M. Caprioli ${ }^{1,2,3,4,5}$. \\ ${ }^{1}$ Department of Chemistry, Vanderbilt University, 7330 Stevenson Center, Station B 351822, Nashville, TN 37235, USA \\ ${ }^{2}$ Mass Spectrometry Research Center, Vanderbilt University, $46521^{\text {st }}$ Ave S \#9160, Nashville, TN 37235, USA \\ ${ }^{3}$ Department of Biochemistry, Vanderbilt University, 607 Light Hall, Nashville, TN 37205, USA \\ ${ }^{4}$ Department of Pharmacology, Vanderbilt University, 2220 Pierce Avenue, Nashville, TN 37232, USA \\ ${ }^{5}$ Department of Medicine, Vanderbilt University, $116121^{\text {st }}$ Ave S, Nashville, TN 37232, USA
}

\begin{abstract}
KEYWORDS. Imaging mass spectrometry, Matrix-assisted laser desorption/ionization, MALDI-2, post-ionization, peptide mass fingerprinting
\end{abstract}

\begin{abstract}
Matrix-assisted laser desorption/ionization imaging mass spectrometry (MALDI IMS) allows for the highly multiplexed, unlabeled mapping of analytes from thin tissue sections but further work is needed to improve sensitivity and depth of coverage for protein and peptide IMS. Laser-based post-ionization (MALDI-2) has been shown to increase sensitivity for numerous molecular classes for MALDI but this has not been demonstrated for peptides. Here, we demonstrate signal enhancement of proteolytic peptides from thin tissue sections of human kidney with MALDI-2. Proteins were digested in situ using trypsin prior to the IMS analysis with MALDI (here, MALDI-1) and MALDI-2. For identification of peptides and proteins from MALDI IMS, a tissue homogenate was analyzed via LC-MS/MS for bottom-up proteomics and the proteins identified via LC-MS/MS were further 'digested' in silico to generate a database of theoretical peptides to match to MALDI IMS data sets. Peptides were tentatively identified by matching the MALDI peak list to the database within 5 ppm error that resulted in $170 \pm 37$ peptides and $885 \pm 73$ peptides for MALDI-1 and MALDI-2, respectively. Protein identifications were similarly made by linking IMS data to LC-MS/MS results wherein positive identifications required two or more peptides to be detected per associated protein. This resulted in $55 \pm 13$ proteins identified with MALDI-1 and $205 \pm 10$ with MALDI-2. MALDI-2 provides enhanced sensitivity for the spatial mapping of tryptic peptides and it greatly increases the number of proteins identified during IMS experiments.
\end{abstract}

The spatial mapping of peptides and proteins is crucial for understanding the underlying molecular drivers of tissue biology and pathology. ${ }^{1-8}$ Protein distributions in tissue are highly dependent on expression within cell types and on molecular changes in the tissue microenvironment. ${ }^{9-13}$ Traditionally, peptides and proteins are identified via mass spectrometry (MS)based proteomic analysis from bulk tissue homogenates, but spatial information is not typically retained with these methods. In contrast, tissue imaging using immunohistochemistry allows for sensitive analyte detection and high spatial resolution mapping, but this approach requires a priori information and is limited in the number of targets that can be imaged in a single experiment. Matrix-assisted laser desorption/ionization imaging mass spectrometry (MALDI IMS) of peptides and proteins combines the advantages of both MS and immunohistochemistry by providing high sensitivity and specificity analyte detection as well as untargeted, multiplexed mapping of hundredsto-thousands of peptides and proteins from a single experiment.

Protein IMS allows for the intact detection of large proteins up to $200 \mathrm{kDa}^{14}$ but the practical upper mass limit is $\sim 50 \mathrm{kDa}$ for time-of-flight (TOF) instruments. ${ }^{15-18}$ High performance mass analyzers (e.g. FT-ICR and Orbitrap) provide superior mass resolving power and accuracy but have limited ion transmission efficiency at high $\mathrm{m} / \mathrm{z}$ and analyses are typically limited to $<30 \mathrm{kDa}$ for protein IMS epxeriments. ${ }^{19-22}$ Much of the proteome is comprised of proteins that are larger than what is typically detectable by IMS and are therefore inaccessible via
MALDI analysis. To access larger proteins, bottom-up IMS experiments are performed by applying a proteolytic enzyme such as trypsin to the tissue surface and imaging the resulting peptides. ${ }^{23-28}$ Using mass accuracy, multiple peptides with similar localization that match to a single protein are used for tentative protein identification. ${ }^{23,24}$

Although peptide and protein IMS workflows are routine, proteomic coverage and sensitivity remain as challenges. Strategies to improve sensitivity through sample preparation approaches have included development of novel MALDI matri$\operatorname{ces}^{29,30}$ and tissue washes to remove interfering lipid and metabolite species that suppress peptide signals. ${ }^{31-33}$ Other approaches include denaturing proteins using methods such as antigen retrieval to allow trypsin to access more sites for digestion. ${ }^{25}$ Digestion condition variables such as time, temperature, and humidity have also been optimized to improve digestion efficiency while maintaining peptide localization within a tissue section. ${ }^{27,34}$ Still, increased sensitivity is needed to improve proteomic coverage for bottom-up IMS experiments.

Many instrumental technologies can be employed for improving sensitivity for IMS experiments. ${ }^{35-39}$ One technology that has been shown to dramatically increase signal for MALDI IMS is laser-based post-ionization. ${ }^{40-45}$ MALDI IMS allows for detection of intact molecules with good sensitivity but an abundance of neutrals are generated during the initial MALDI event (MALDI-1) that remain undetected. Post-ionization deposits energy into this plume of neutral molecules to enhance 
ionization. Laser based post-ionization (MALDI-2) uses a secondary laser positioned parallel to, and above the sample to irradiate the plume generated by the initial MALDI event thereby increasing the fraction of molecules that are ionized. MALDI-2 has been shown to increase ion intensity up to 100-fold and the number of identified species $\sim 2 x$ for lipids. ${ }^{41,43}$ MALDI-2 postionization has been demonstrated to increase intensity for many classes of biologically relevant analytes including lipids, ${ }^{40-}$ 43,45,46 saccharides ${ }^{40}$ liposoluble vitamins, ${ }^{40} \mathrm{~N}$-linked glycans, ${ }^{47}$ certain pharmaceutical compounds, ${ }^{46}$ and protein complexes ${ }^{48}$ but to our knowledge, MALDI-2 post-ionization has not been demonstrated for IMS of tryptic peptides. Here, we demonstrate the use of MALDI-2 post-ionization for the enhancement of tryptic peptides from human kidney thin tissue sections.

To evaluate the feasibility of using MALDI-2 for IMS of tryptic peptides, sections of fresh frozen human kidney were prepared in technical triplicate. Human kidney tissues were collected as part of normal non-neoplastic portions of nephrectomy samples. Tissue blocks were frozen using an isopentane/dry ice slurry, embedded in carboxymethyl cellulose, and cryosectioned at $10 \mu \mathrm{m}$ thickness. Sections were washed to remove the carboxymethyl cellulose embedding material using ethanol and water ${ }^{49}$. A Carnoy's solution wash protocol was used to remove salts and lipids. Antigen retrieval was performed to thermally denature the proteins prior to trypsin application with a pneumatic sprayer, as previously described ${ }^{25}$ and samples were digested at $37^{\circ} \mathrm{C}$, overnight in a humidity oven (Espec North America) set to $100 \%$ relative humidity. The MALDI matrix $\alpha$ cyano-4-hydroxy-cinnamic acid was applied via pneumatic sprayer (HTX Technologies, LLC). Tissue sections were analyzed in positive ion mode at $50 \mu \mathrm{m}$ spatial resolution using an Orbitrap Elite instrument equipped with a MALDI ion source (Spectroglyph, LLC) which included a second laser for MALDI-2 functionality (266 nm, CryLaS, GmbH) as described previously. ${ }^{43}$ Samples were analyzed with MALDI-1 and MALDI-2 with similar and adjacent regions of the same section and the ion images contained a comparable number of pixels ( 15 000 in each region). Sample preparation for peptides was optimized to maximize signal with MALDI-1 and to maintain the spatial distribution of peptides across the tissue. Averaged spectra were deisotoped and peak picked based on a signal-tonoise ratio $(\mathrm{S} / \mathrm{N})$ of 10 . A comparison of representative averaged mass spectra generated from both analysis modes is displayed in Figure 1. Analysis with MALDI-1 resulted in 515 peaks whereas MALDI-2 allowed for detection of 1443 peaks. Additionally, the overall spectral intensity is greater with MALDI-2 $\left(2.6 \times 10^{3}\right)$ as compared to MALDI-1 $\left(8.0 \times 10^{2}\right)$. These data show that there are significant signal and molecular coverage improvements for peptide IMS experiments with MALDI-2.

For IMS visualization, ion images were converted to vendor-neutral imzML format using ImageInsight software (Spectroglyph, LLC) and imported into SCiLS (Bruker, version $2019 b$ ). The IMS data were processed with root mean square normalization prior to image generation. Example ions and their localization compared to an autofluorescence image obtained of the same tissue section prior to analysis ${ }^{50}$ are shown in Figure 2. The human kidney tissue sections analyzed contain the major functional units of the kidney including the cortex, medulla, and glomeruli. Highlighted ion images were selected to provide
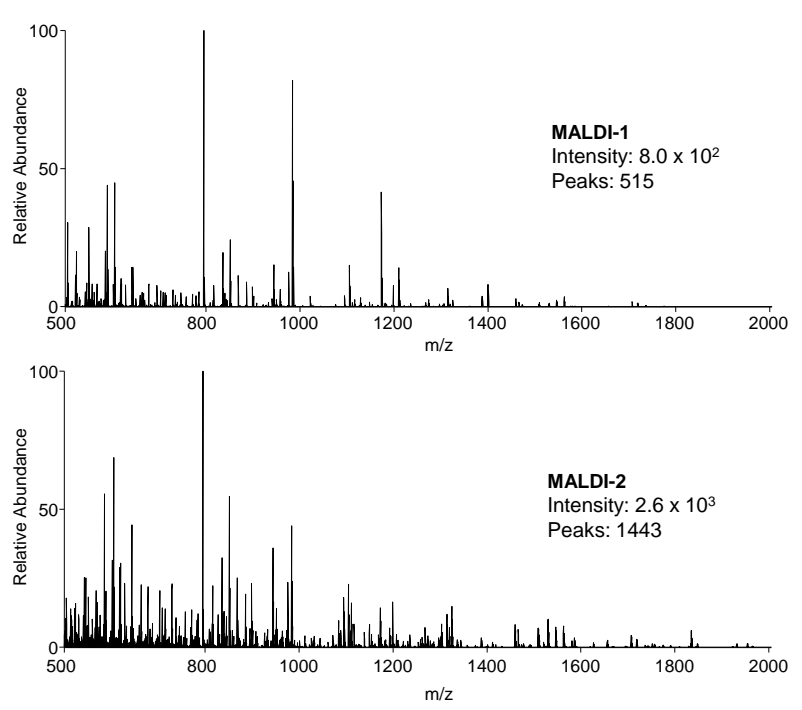

Figure 1. Average mass spectrum of ion images with (A) MALDI-1 and (B) MALDI-2 from IMS of digested human kidney sections. The increase in sensitivity and number of peaks in the mass range of peptides $(\mathrm{m} / \mathrm{z}, 1000-2000)$ demonstrates peptide signal increases with MALDI-2. Number of peaks for MALDI-1 (515) and MALDI-2 (1443) are based on a signal-to-noise ratio of 10 with isotopes removed.

examples of peptides that localize to these regions and ubiquitously across the tissue (Figure 2 B-E).

Peptide identification from IMS data was performed in three steps. First, a tissue homogenate was analyzed via bottom-up LC-MS/MS proteomics. Detailed protocols are available on Protocols.io. ${ }^{51-55}$ Briefly, tissue sections were homogenized and digested with trypsin, data was acquired on an Thermo Fusion Tribrid mass spectrometer, and the data were analyzed using MaxQuant. ${ }^{56,57} \mathrm{Next}$, the identified proteins were digested in silico using a local installation of Protein Prospector (prospector.ucsf.edu) to obtain a database of all possible tryptic peptides. Finally, deisotoped IMS peak lists from MALDI- 1 and MALDI-2 analysis (with $\mathrm{S} / \mathrm{N}$ of 10 or greater) were compared to the peptide data from the in silico digestion. The database constructed via in silico digestion contained 144,619 unique peptides to compare with IMS data. While this could potentially increase the number of false positives for proteins, this approach allows for annotation of possible peptides detected via MALDI-1 and MALDI-2 that may have gone undetected during LC-MS/MS analysis. The theoretical $\mathrm{m} / \mathrm{z}$ values of protonated peptides from the in silico digestion were matched to peak lists from the average IMS mass spectra with a mass tolerance of $5 \mathrm{ppm}$. Protein identification was completed via peptide mass fingerprinting wherein the detection of two or more peptides corresponding to the same protein was used for protein identification. $^{34,58}$ To deal with multiple peptide matches to a single MALDI ion, a simple scoring system was implemented that 1) ranked proteins in the LC-MS/MS dataset 


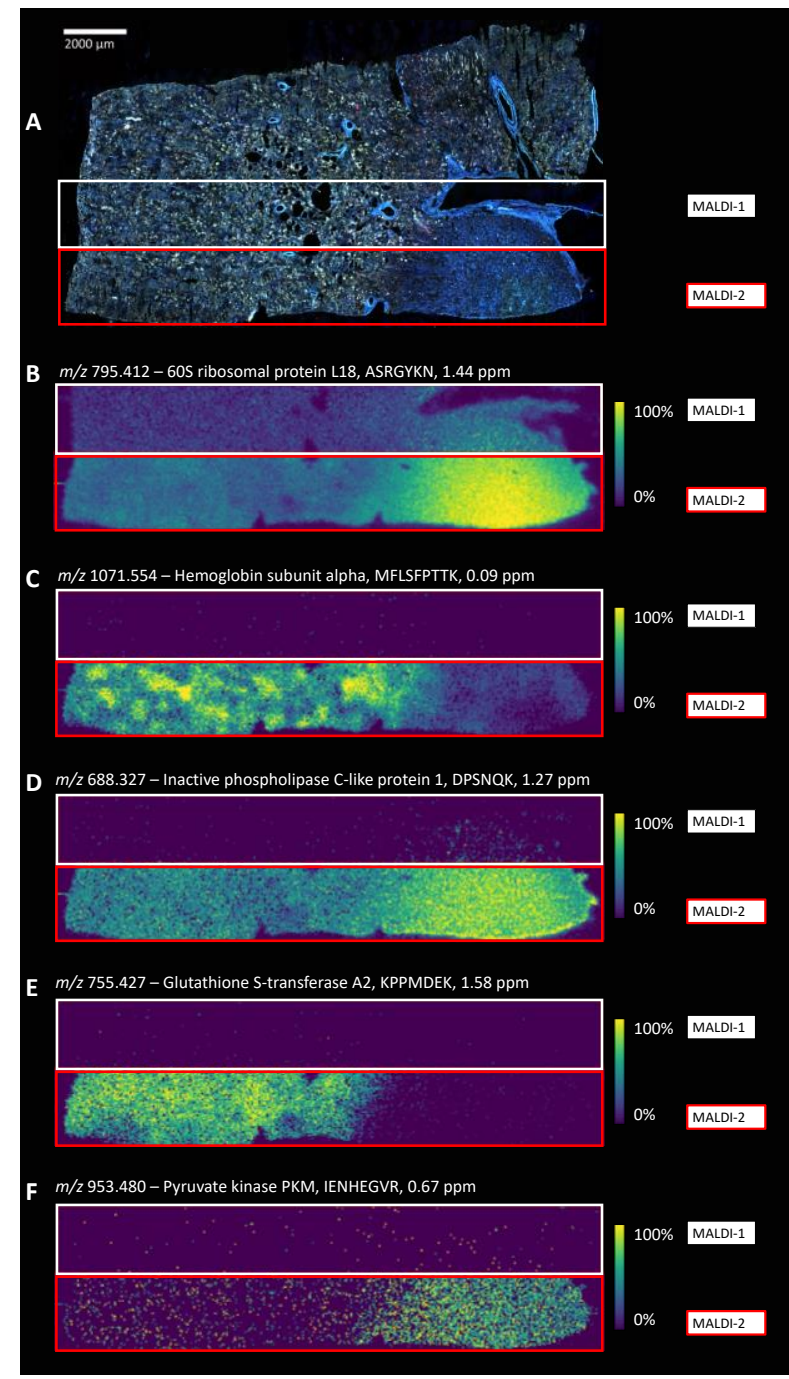

Figure 2. Autofluorescence image of human kidney (A) and ion images (B-F) of peptides that localize to different tissue functional units of the kidney including the glomeruli $(\mathrm{C})$, cortex $(\mathrm{E})$, medulla $(\mathrm{F})$, and throughout the tissue $(\mathrm{B}$, D). Ion images were obtained via MALDI-1 (white outline, above) and MALDI-2 (red outline, below). Some species showed little change in intensity between MALDI-1 and MALDI-2 (B) while many species dramatically increased with MALDI-2 (C-F). Ion $\mathrm{m} / \mathrm{z}$ values, protein identity, amino acid sequence of peptide, and mass error are listed and are based on accurate mass measurements matched to LC-MS/MS data within $\pm 5 \mathrm{ppm}$ error for each peptide where at least two peptides per protein were detected with similar localization. The autofluorescence image of the tissue section (A) was acquired prior to IMS analysis.

using sequence coverage and the number of identified peptides per protein normalized to molecular weight and 2) ranked the mass accuracy of the MALDI-to-peptide matches as well as the number of potential peptides per protein for each match. It also considered the number of potential matches with the same mass difference. These parameters and their optimization will be further discussed in a forthcoming publication.

Many peptides that were not detected with MALDI-1 alone were detected with MALDI-2 (Figure 2 C-F) and

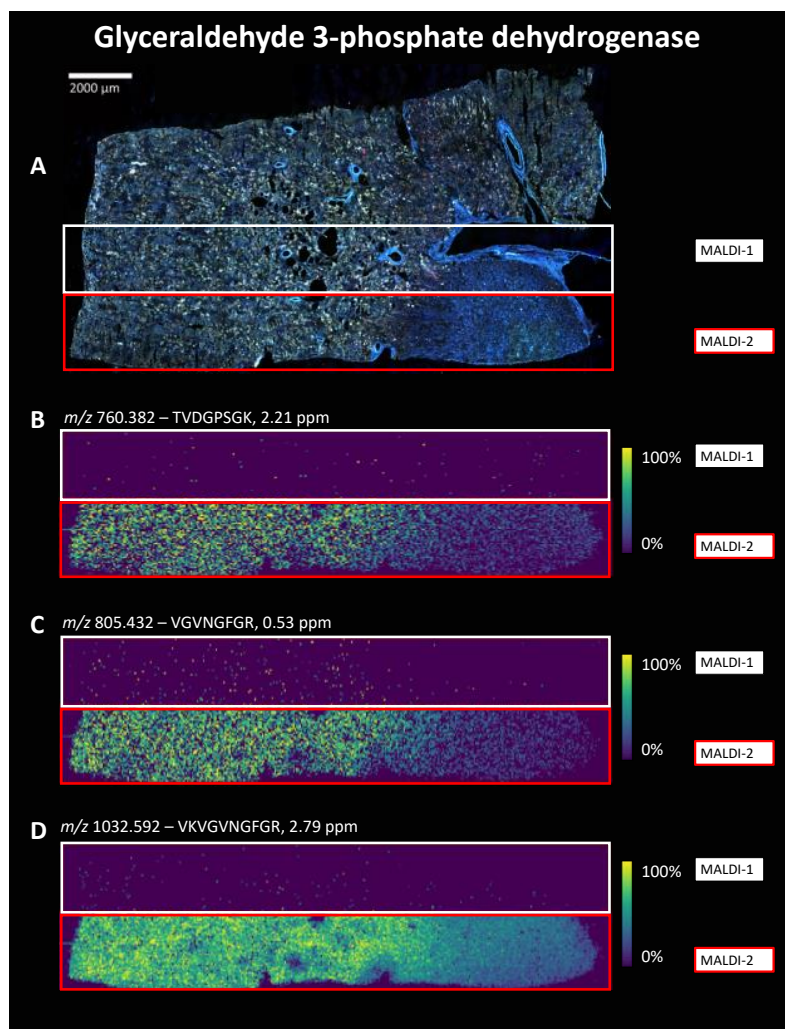

Figure 3. Autofluorescence image of human kidney (A) and ion images (B-E) showing multiple peptide matches to the protein glyceraldehyde 3-phosphate dehydrogenase. Amino acid sequence and measured mass of each peptide is listed above the ion image. Eight peptides within $\pm 5 \mathrm{ppm}$ mass error to the theoretical value were detected via IMS and match to peptides detected in LC-MS/MS data. Three representative peptides are shown here, full data is displayed in Supplementary Figure S8. Peptides localize similarly in the tissue (here, throughout the tissue but predominantly in the cortex) which is expected from species relating to the same identified protein.

MALDI-2 provided improved sensitivity for many ions already detectable with MALDI-1 (Figure 2 B). Complementary ion images for the identified proteins in Figure $\mathbf{2}$ are shown in Figures S1-S5. Further, MALDI-2 provided for enhanced signal for $99 \%$ of identified peptides (986/988) from a representative sample. One peptide that decreased with MALDI-2 did not match the localization within tissue as the other peptides for that protein. The other peptide that decreased with MALDI-2 was identified as part of the protein Filamin B and the related peptide ion images are shown in Figure S6 where the other peptides increase with MALDI-2. Peptide signal decrease with MALDI2 may be based on matrix adduct formation or selective photoionization as proposed by others for lipids. ${ }^{41}$ To determine if certain amino acids or molecular characteristics affect MALDI2 of peptides, amino acid composition analysis was performed on peptides from the three samples (Figure S7). Significant differences in amino acid composition was discovered but no trend in specific amino acid characteristics such as acidity/basicity, polarity, or charge was elucidated. Additionally, peptide hydropathy values for each peptide were calculated based on peptide grand averages of hydropathy using amino acid hydropathy values from Kyte and Doolittle ${ }^{5,59}$ but no difference in 
distribution of average hydropathy values was observed (Figure S8). These results seem to be consistent with the ionization mechanisms previously proposed for MALDI-2. It is thought that MALDI-2 proceeds via multiphoton ionization of matrix to form charged radicals and transfer charge to neutral analytes. ${ }^{45,60,61}$ This results in a reversal of ion suppression effects for some analytes.. This reversal of ion suppression effects has been demonstrated for analysis of lipids and certain classes of phospholipids readily ionizable not increase significantly upon irradiation with MALDI-2. ${ }^{43,44}$ These data suggest that the peptide signal enhancement with MALDI-2 may be similar to that proposed for lipids by reversing MALDI ion suppression effects irrespective of the peptide amino acid composition.

Overall, IMS with MALDI-2 and subsequent protein identification via peptide mass fingerprinting allowed for identification of 1,112 \pm 84 unique peptides and $428 \pm 20$ unique proteins, $205 \pm 10$ of which were identified by 2 or more peptides. In comparison, MALDI-1 alone led to the identification of $314 \pm 45$ unique peptides and $197 \pm 19$ proteins, $55 \pm 13$ of which had 2 or more peptides. On average, $69 \pm 3 \%$ peaks in the MALDI-1 spectrum were identified as peptides; this increased to $86 \pm 1 \%$ for MALDI- 2 . Of the unique peptides identified in the MALDI average spectra, $6.3 \%$ and $8.3 \%$ of the peptides for MALDI-1 and MALDI-2 respectively were found in the LC-MS/MS dataset. MALDI and ESI-LC-MS/MS generally identify different sets of peptides. ${ }^{5,62,63}$ In our case, a reason for poor matching between the MALDI and LC-MS/MS datasets appears to be peptide size. In the MALDI dataset, the median number of amino acids per peptide was 5.8, with a minimum of 5. Peptides identified by LC-MS/MS had a median amino acid number of 13 with a minimum of 7 . Previously, it has been noted that MALDI identified larger peptides compared to LC$\mathrm{MS} / \mathrm{MS}^{63}$; however, differences in acquisition parameters such as $\mathrm{m} / \mathrm{z}$ range could explain the discrepancy. Since the in silico digest contained all theoretical peptides, this approach identified small peptides that were not identified from the LCMS/MS dataset and therefore the number of peptides that could be identified in the MALDI data significantly improved.

Protein identification significantly improved, and one example protein only identified with MALDI-2 is glyceraldehyde 3-phosphate dehydrogenase. Glyceraldehyde 3phosphate dehydrogenase is overexpressed in kidney and liver cancer and liver tumorigenesis compared with healthy tissue. ${ }^{64}$ ${ }^{66}$ The ion images of its corresponding peptides are shown in Figure 3 and Figure S9. An optical autofluorescence image of the tissue was obtained prior to sample preparation (Figure 3 A) and the IMS acquisition regions of MALDI-1 and MALDI2 are shown in the white and red rectangular outlines, respectively. Ion images for peptides are shown (Figure 3 B-E) where each identified peptide was contained in the theoretical peptide database and matched to the IMS data as described above. Here, the protein was not detected with MALDI-1 but was detected with MALDI-2 and the peptides are shown to localize to the cortex of the kidney.

MALDI-2 allows for the identification of numerous proteins that are not identified with MALDI-1 alone and these proteins may provide insight into important biological functions and disease states as shown in Figure 3. Other proteins identified with MALDI-2 with clinical significance include alphaenolase ${ }^{67,68}$, peroxiredoxin- $1^{69,70}$, and phosphoglycerate kinase $1^{11,71}$ which are elevated in some cancers and tumors. These proof-of-concept experiments demonstrate the utility of MALDI-2 for enhanced detection of peptides from thin tissue sections for bottom-up protein IMS. It is important to note that, although these results show significant promise for peptide IMS, sample preparation methods used were developed for MALDI-1. There is the potential for improving MALDI-2 performance further by optimizing sample preparation and matrices for laser-based post-ionization, specifically. This technology will be beneficial for future studies of disease states to obtain both protein identity and corresponding spatial distribution of clinically relevant peptide and protein species in relation to certain functional tissue units and will provide information toward more targeted therapeutics. These technical improvements are also critical for providing more robust and complete molecular imaging capabilities for large-scale tissue mapping projects such as the Human Biomolecular Atlas Program (HuBMAP), which will help provide a systems biology view on the molecular drivers of health and disease.

\title{
ASSOCIATED CONTENT
}

\author{
Supporting Information
}

Figure S1: Peptide ion images corresponding to the protein identified as 60 S ribosomal protein L18. Figure S2: Peptide ion images corresponding to the protein identified as Hemoglobin subunit alpha. Figure S3: Peptide ion images corresponding to the protein identified as Inactive phospholipase C-like protein 1. Figure S4: Peptide ion images corresponding to the protein identified as Glutathione S-transferase A2. Figure S5: Peptide ion images corresponding to the protein identified as Pyruvate Kinase PKM. Figure S6: Peptide ion images corresponding to the protein identified as Filamin B. Figure S7: Amino acid composition of identified peptides. Figure S8: Amino acid grand average of hydropathy (GRAVY) of peptides detected via MALDI-1 and MALDI-2. Figure S9: Peptide ion images corresponding to the protein identified as Glyceraldehyde 3-phosphate dehydrogenase.

\section{AUTHOR INFORMATION}

\author{
Corresponding Author \\ * Jeffrey M. Spraggins, Jeff.Spraggins@vanderbilt.edu \\ Jeffrey M. Spraggins: 0000-0001-9198-5498 \\ Josiah C. McMillen: 0000-0002-1095-695X \\ Danielle B. Gutierrez: 0000-0001-6355-2134 \\ Audra M. Judd: 0000-0002-4633-129X \\ Richard M. Caprioli: 0000-0001-5859-3310
}




\section{Author Contributions}

All authors have given approval to the final version of the manuscript.

\section{ACKNOWLEDGMENT}

Support was provided by the NIH Common Fund and National Institute of Diabetes and Digestive and Kidney Diseases (U54DK120058 awarded to J.M.S. and R.M.C.), the NIH Common Fund and National Eye Institute (U54EY032442), and by the NIH National Institute of General Medical Sciences (2P41GM103391 awarded to R.M.C.). Human tissues were acquired through the Cooperative Human Tissue Network at Vanderbilt University Medical Center which is supported by the NIH National Cancer Institute (5 UM1 CA183727-08).

\section{REFERENCES}

(1) Caprioli, R. M.; Farmer, T. B.; Gile, J. Molecular Imaging of Biological Samples: Localization of Peptides and Proteins Using MALDI-TOF MS. Anal. Chem. 1997, 69 (23), 4751-4760. https://doi.org/10.1021/AC970888I.

(2) Andersson, M.; Groseclose, M. R.; Deutch, A. Y.; Caprioli, R. M Imaging Mass Spectrometry of Proteins and Peptides: 3D Volume Reconstruction. Nat. Methods 2008, 5 (1), 101-108. https://doi.org/10.1038/nmeth1145.

(3) Taban, I. M.; Altelaar, A. F. M.; van der Burgt, Y. E. M.; McDonnell, L. A.; Heeren, R. M. A.; Fuchser, J.; Baykut, G. Imaging of Peptides in the Rat Brain Using MALDI-FTICR Mass Spectrometry. J. Am. Soc. Mass Spectrom. 2007, 18 (1), 145-151. https://doi.org/10.1016/j.jasms.2006.09.017.

Taira, S.; Sugiura, Y.; Moritake, S.; Shimma, S.; Ichiyanagi, Y.; Setou, M. Nanoparticle-Assisted Laser Desorption/Ionization Based Mass Imaging with Cellular Resolution. https://doi.org/10.1021/ac800081z.

Maria Nadler, W.; Waidelich, D.; Kerner, A.; Hanke, S.; Berg, R.; Trumpp, A.; Ro, C. MALDI versus ESI: The Impact of the Ion Source on Peptide Identification. J. Proteome Res. 2017, 16, 1207-1215. https://doi.org/10.1021/acs.jproteome.6b00805.

McDonnell, L. A.; Corthals, G. L.; Willems, S. M.; van Remoortere, A.; van Zeijl, R. J. M.; Deelder, A. M. Peptide and Protein Imaging Mass Spectrometry in Cancer Research. $J$. Proteomics 2010, 73 (10), 1921-1944. https://doi.org/10.1016/j.jprot.2010.05.007.

Altelaar, A. F. M.; Taban, I. M.; McDonnell, L. A.; Verhaert, P. D. E. M.; de Lange, R. P. J.; Adan, R. A. H.; Mooi, W. J.; Heeren, R. M. A.; Piersma, S. R. High-Resolution MALDI Imaging Mass Spectrometry Allows Localization of Peptide Distributions at Cellular Length Scales in Pituitary Tissue Sections. Int. J. Mass Spectrom. 2007, $260 \quad$ (2-3), 203-211. https://doi.org/10.1016/j.ijms.2006.09.028.

Lemaire, R.; Wisztorski, M.; Desmons, A.; Tabet, J. C.; Day, R. Salzet, M.; Fournier, I. MALDI-MS Direct Tissue Analysis of Proteins: Improving Signal Sensitivity Using Organic Treatments. Anal. Chem. 2006, 78 (20), 7145-7153. https://doi.org/10.1021/ac060565z.

Wisztorski, M.; Desmons, A.; Quanico, J.; Fatou, B.; Gimeno, J.P.; Franck, J.; Salzet, M.; Fournier, I. Spatially-Resolved Protein Surface Microsampling from Tissue Sections Using Liquid Extraction Surface Analysis. Proteomics 2016, 16 (11-12), 1622-1632. https://doi.org/10.1002/pmic.201500508.

(10) Swales, J. G.; Dexter, A.; Hamm, G.; Nilsson, A.; Strittmatter, N.; Michopoulos, F.; Hardy, C.; Morentin-Gutierrez, P.; Mellor, M.; Andren, P. E.; et al. Quantitation of Endogenous Metabolites in Mouse Tumors Using Mass-Spectrometry Imaging. Anal. Chem. 2018, $90 \quad$ (10), 6051-6058 https://doi.org/10.1021/acs.analchem.7b05239.
Wang, J.; Ying, G.; Wang, J.; Jung, Y.; Lu, J.; Zhu, J.; Pienta, K. J.; Taichman, R. S. Characterization of Phosphoglycerate Kinase1 Expression of Stromal Cells Derived from Tumor Microenvironment in Prostate Cancer Progression. Cancer Res. 2010, 70 (2), 471-480. https://doi.org/10.1158/0008-5472.CAN09-2863.

(12) Angel, P. M.; Schwamborn, K.; Comte-Walters, S.; Clift, C. L.; Ball, L. E.; Mehta, A. S.; Drake, R. R. Extracellular Matrix Imaging of Breast Tissue Pathologies by MALDI-Imaging Mass Spectrometry. PROTEOMICS - Clin. Appl. 2019, 13 (1), 1700152. https://doi.org/10.1002/prca.201700152.

(13) Chughtai, K.; Jiang, L.; Greenwood, T. R.; Glunde, K.; Heeren, R. M. A. Mass Spectrometry Images Acylcarnitines, Phosphatidylcholines, and Sphingomyelin in MDA-MB-231 Breast Tumor Models. J. Lipid Res. 2013, 54 (2), 333-344. https://doi.org/10.1194/jlr.M027961.

(14) Ludwig, K.; Habbach, S.; Krieglstein, J.; Klumpp, S.; König, S MALDI-TOF High Mass Calibration up to $200 \mathrm{KDa}$ Using Human Recombinant $16 \mathrm{KDa}$ Protein Histidine Phosphatase Aggregates. PLoS One 2011, 6 (8), e23612. https://doi.org/10.1371/journal.pone.0023612.

(15) Gessel, M. M.; Norris, J. L.; Caprioli, R. M. MALDI Imaging Mass Spectrometry: Spatial Molecular Analysis to Enable a New Age of Discovery. J. Proteomics 2014, 107, 71-82. https://doi.org/10.1016/J.JPROT.2014.03.021.

(16) Spraggins, J. M.; Caprioli, R. M. High-Speed MALDI-TOF Imaging Mass Spectrometry: Rapid Ion Image Acquisition and Considerations for Next Generation Instrumentation. J. Am. Soc. Mass Spectrom. 2011, 22 (6), 1022-1031. https://doi.org/10.1007/s13361-011-0121-0.

(17) Yang, J.; Caprioli, R. M. Matrix Sublimation/Recrystallization for Imaging Proteins by Mass Spectrometry at High Spatial Resolution. | Anal. Chem 2011, 83, 5728-5734. https://doi.org/10.1021/ac200998a.

(18) Zavalin, A.; Yang, J.; Hayden, K.; Vestal, M.; Caprioli, R. M Tissue Protein Imaging at $1 \mathrm{Mm}$ Laser Spot Diameter for High Spatial Resolution and High Imaging Speed Using Transmission Geometry MALDI TOF MS. Anal. Bioanal. Chem. 2015, 407 (8), 2337-2342. https://doi.org/10.1007/s00216-015-8532-6.

(19) Prentice, B. M.; Ryan, D. J.; Van de Plas, R.; Caprioli, R. M.; Spraggins, J. M. Enhanced Ion Transmission Efficiency up to $\mathrm{m} / \mathrm{z}$ 24000 for MALDI Protein Imaging Mass Spectrometry. Anal. $\begin{array}{llll}\text { Chem. } & \text { 2018, } & 90 & \text { (8), 5090-5099. }\end{array}$ https://doi.org/10.1021/acs.analchem.7b05105.

(20) Spraggins, J. M.; Rizzo, D. G.; Moore, J. L.; Noto, M. J.; Skaar, E. P.; Caprioli, R. M. Next-Generation Technologies for Spatial Proteomics: Integrating Ultra-High Speed MALDI-TOF and High Mass Resolution MALDI FTICR Imaging Mass Spectrometry for Protein Analysis. Proteomics 2016, 16 (11-12), 
1678-1689. https://doi.org/10.1002/pmic.201600003.

(21)

Piga, I.; Heijs, B.; Nicolardi, S.; Giusti, L.; Marselli, L.; Marchetti, P.; Mazzoni, M. R.; Lucacchini, A.; McDonnell, L. A. Ultra-High Resolution MALDI-FTICR-MSI Analysis of Intact Proteins in Mouse and Human Pancreas Tissue. Int. J. Mass Spectrom. 2019, 437, 10-16. https://doi.org/10.1016/j.ijms.2017.11.001.

(22) Spraggins, J. M.; Rizzo, D. G.; Moore, J. L.; Rose, K. L.; Hammer, N. D.; Skaar, E. P.; Caprioli, R. M. MALDI FTICR IMS of Intact Proteins: Using Mass Accuracy to Link Protein Images with Proteomics Data. J. Am. Soc. Mass Spectrom. 2015, 26 (6), 947-985. https://doi.org/10.1007/s13361-015-1147-5.

(23) Minerva, L.; Boonen, K.; Menschaert, G.; Landuyt, B.; Baggerman, G.; Arckens, L. Linking Mass Spectrometric Imaging and Traditional Peptidomics: A Validation in the Obese Mouse Model. Anal. Chem. 2011, 83 (20), 7682-7691. https://doi.org/10.1021/ac200888j.

(24) Gustafsson, J. O. R.; Oehler, M. K.; McColl, S. R.; Hoffmann, P. Citric Acid Antigen Retrieval (CAAR) for Tryptic Peptide Imaging Directly on Archived Formalin-Fixed ParaffinEmbedded Tissue. J. Proteome Res. 2010, 9 (9), 4315-4328. https://doi.org/10.1021/pr9011766.

(25) Judd, A. M.; Gutierrez, D. B.; Moore, J. L.; Patterson, N. H.; Yang, J.; Romer, C. E.; Norris, J. L.; Caprioli, R. M. A Recommended and Verified Procedure for in Situ Tryptic Digestion of Formalin-Fixed Paraffin-Embedded Tissues for Analysis by Matrix-Assisted Laser Desorption/Ionization Imaging Mass Spectrometry. J. Mass Spectrom. 2019, 54 (8), 716-727. https://doi.org/10.1002/jms.4384.

(26) Groseclose, M. R.; Andersson, M.; Hardesty, W. M.; Caprioli, R. M. Identification of Proteins Directly from Tissue: In Situ Tryptic Digestions Coupled with Imaging Mass Spectrometry. J. Mass Spectrom. $\quad \mathbf{2 0 0 7}, \quad 42 \quad$ (2), 254-262. https://doi.org/10.1002/jms.1177.

(27) Angel, P. M.; Mehta, A.; Norris-Caneda, K.; Drake, R. R. MALDI Imaging Mass Spectrometry of N-Glycans and Tryptic Peptides from the Same Formalin-Fixed, Paraffin-Embedded Tissue Section. In Methods in Molecular Biology; Sarwal, M. M., Sigdel, T. K., Eds.; New York, NY, 2018; Vol. 1788, pp 225241. https://doi.org/10.1007/7651_2017_81.

(28) Pietrowska, M.; Gawin, M.; Polańska, J.; Widłak, P. Tissue Fixed with Formalin and Processed without Paraffin Embedding Is Suitable for Imaging of Both Peptides and Lipids by MALDIIMS. Proteomics 2016, 16 (11-12), 1670-1677. https://doi.org/10.1002/pmic.201500424.

(29) Crank, J. A.; Armstrong, D. W. Towards a Second Generation of Ionic Liquid Matrices (ILMs) for MALDI-MS of Peptides, Proteins, and Carbohydrates. J. Am. Soc. Mass Spectrom. 2009, $20 \quad(10), \quad 1790-1800$. https://doi.org/10.1016/j.jasms.2009.05.020.

(30) Laugesen, S.; Roepstorff, P. Combination of Two Matrices Results in Improved Performance of MALDI MS for Peptide Mass Mapping and Protein Analysis. J Am Soc Mass Spectrom 2003, 14 (9), 992-1002. https://doi.org/10.1016/S10440305(03)00262-9.

(31) Seeley, E. H.; Oppenheimer, S. R.; Mi, D.; Chaurand, P.; Caprioli, R. M. Enhancement of Protein Sensitivity for MALDI
Imaging Mass Spectrometry After Chemical Treatment of Tissue Sections. J. Am. Soc. Mass Spectrom. 2008, 19 (8), 1069-1077. https://doi.org/10.1016/j.jasms.2008.03.016.

Gustafsson, J. O. R.; Oehler, M. K.; Ruszkiewicz, A.; McColl, S. R.; Hoffmann, P. MALDI Imaging Mass Spectrometry (MALDIIMS)-Application of Spatial Proteomics for Ovarian Cancer Classification and Diagnosis. Int. J. Mol. Sci. 2011, 12 (1), 773 794. https://doi.org/10.3390/ijms12010773.

Thomas, A.; Patterson, N. H.; Laveaux Charbonneau, J.; Chaurand, P. Orthogonal Organic and Aqueous-Based Washes of Tissue Sections to Enhance Protein Sensitivity by MALDI Imaging Mass Spectrometry. J. Mass Spectrom. 2013, 48 (1), 4248. https://doi.org/10.1002/jms.3114.

(34) Cillero-Pastor, B.; Heeren, R. M. A. Matrix-Assisted Laser Desorption Ionization Mass Spectrometry Imaging for Peptide and Protein Analyses: A Critical Review of On-Tissue Digestion. 2013. https://doi.org/10.1021/pr400743a.

Spraggins, J.; Djambazova, K.; Rivera, E.; Migas, L.; Neumann, E.; Fuetterer, A.; Suetering, J.; Goedecke, N.; Ly, A.; Van de Plas, R.; et al. High Performance Molecular Imaging with MALDI Trapped Ion Mobility Time-of-Flight (TimsTOF) Mass Spectrometry. 2019. https://doi.org/10.26434/CHEMRXIV.9210059.V1.

(36) Djambazova, K. V.; Klein, D. R.; Migas, L. G.; Neumann, E. K.; Rivera, E. S.; Van de Plas, R.; Caprioli, R. M.; Spraggins, J. M. Resolving the Complexity of Spatial Lipidomics Using MALDI TIMS Imaging Mass Spectrometry. Anal. Chem. 2020, 92 (19), 13290-13297. https://doi.org/10.1021/acs.analchem.0c02520.

(37) Prentice, B. M.; Ryan, D. J.; Grove, K. J.; Cornett, D. S.; Caprioli, R. M.; Spraggins, J. M. Dynamic Range Expansion by Gas-Phase Ion Fractionation and Enrichment for Imaging Mass Spectrometry. Anal. Chem. 2020, 92 (19), 13092-13100. https://doi.org/10.1021/acs.analchem.0c02121.

(38) Pfammatter, S.; Bonneil, E.; McManus, F. P.; Prasad, S.; Bailey, D. J.; Belford, M.; Dunyach, J. J.; Thibault, P. A Novel Differential Ion Mobility Device Expands the Depth of Proteome Coverage and the Sensitivity of Multiplex Proteomic Measurements. Mol. Cell. Proteomics 2018, 17 (10), 2051-2067. https://doi.org/10.1074/mcp.TIR118.000862.

Vasilopoulou, C. G.; Sulek, K.; Brunner, A.-D.; Meitei, N. S.; Schweiger-Hufnagel, U.; Meyer, S. W.; Barsch, A.; Mann, M.; Meier, F. Trapped Ion Mobility Spectrometry and PASEF Enable In-Depth Lipidomics from Minimal Sample Amounts. Nat. Commun. 2020, 11 (1), 331. https://doi.org/10.1038/s41467-01914044-x.

(40) Soltwisch, J.; Kettling, H.; Vens-Cappell, S.; Wiegelmann, M. Müthing, J.; Dreisewerd, K. Mass Spectrometry Imaging with Laser-Induced Postionization. Science (80-. ). 2015, 348 (6231), 211-215. https://doi.org/10.1021/cr010375i.

Ellis, S. R.; Soltwisch, J.; Paine, M. R. L.; Dreisewerd, K.; Heeren, R. M. A. Laser Post-Ionisation Combined with a High Resolving Power Orbitrap Mass Spectrometer for Enhanced MALDI-MS Imaging of Lipids. Chem. Commun. 2017, 53 (53), 7246-7249. https://doi.org/10.1039/C7CC02325A.

Niehaus, M.; Soltwisch, J.; Belov, M. E.; Dreisewerd, K. Transmission-Mode MALDI-2 Mass Spectrometry Imaging of Cells and Tissues at Subcellular Resolution. Nat. Methods 2019, 
(43)

McMillen, J. C.; Fincher, J. A.; Klein, D. R.; Spraggins, J. M.; Caprioli, R. M. Effect of MALDI Matrices on Lipid Analyses of Biological Tissues Using MALDI-2 Post-Ionization Mass $\begin{array}{llll}\text { Spectrometry. } & J & \text { Mass }\end{array}$ https://doi.org/10.1002/JMS.4663.

(44) Boskamp, M. S.; Soltwisch, J. Charge Distribution between Different Classes of Glycerophospolipids in MALDI-MS Imaging. Anal. 2020. https://doi.org/10.1021/acs.analchem.9b05761.

(45) Soltwisch, J.; Heijs, B.; Koch, A.; Vens-Cappell, S.; Ho, J.; Dreisewerd, K. MALDI-2 on a Trapped Ion Mobility Quadrupole Time-of-Flight Instrument for Rapid Mass Spectrometry Imaging and Ion Mobility Separation of Complex Lipid Profiles. 2020, 06, 15. https://doi.org/10.1021/acs.analchem.0c01747.

(46) Barré, F. P. Y.; Paine, M. R. L.; Flinders, B.; Trevitt, A. J.; Kelly, P. D.; Ait-Belkacem, R.; Garcia, J. P.; Creemers, L. B.; Stauber, J.; Vreeken, R. J.; et al. Enhanced Sensitivity Using Maldi Imaging Coupled with Laser Postionization (Maldi-2) for Pharmaceutical Research. Anal. Chem. 2019, 91 (16), 1084010848. https://doi.org/10.1021/acs.analchem.9b02495.

(47) Heijs, B.; Potthoff, A.; Soltwisch, J.; Dreisewerd, K. MALDI-2 for the Enhanced Analysis of $\mathrm{N}$-Linked Glycans by Mass Spectrometry Imaging . Anal. Chem. 2020, 92 (20), 1390413911. https://doi.org/10.1021/acs.analchem.0c02732.

(48) Woods, A. S.; Jackson, S. N.; Lewis, E. K.; Egan, T.; Muller, L.; Tabet, J. C.; Schultz, J. A. MALDI/Post Ionization-Ion Mobility Mass Spectrometry of Noncovalent Complexes of Dopamine Receptors' Epitopes. J. Proteome Res. 2013, 12 (4), 1668-1677. https://doi.org/10.1021/pr301004w.

(49) Anderson, D. M. G.; Lambert, W.; Calkins, D. J.; Ablonczy, Z.; Crouch, R. K.; Caprioli, R. M.; Schey, K. L. Imaging MS of Rodent Ocular Tissues and the Optic Nerve. In Methods in Molecular Biology; Humana Press Inc., 2017; Vol. 1618, pp 1527. https://doi.org/10.1007/978-1-4939-7051-3_3.

(50) Patterson, N. H.; Tuck, M.; Van de Plas, R.; Caprioli, R. M. Advanced Registration and Analysis of MALDI Imaging Mass Spectrometry Measurements through Autofluorescence Microscopy. Anal. Chem. 2018, 90 (21), 12395-12403. https://doi.org/10.1021/acs.analchem.8b02884.

(51) Allen, J.; Spraggins, J.; Gutierrez, D. Automated, Rapid Preparation of Tissue Sections for Proteomic Analysis V.2; 2019. https://doi.org/10.17504/protocols.io.67nhhme.

(52) Gutierrez, D.; Allen, J.; Jenkins, Z.; Spraggins, J. LC-MS/MS Label-Free Proteomic Data Acquisition V.3; 2020. https://doi.org/10.17504/protocols.io.bft3jnqn.

(53) Bowrey, H. E.; Anderson, D. M.; Pallitto, P.; Gutierrez, D. B.; Fan, J.; Crouch, R. K.; Schey, K. L.; Ablonczy, Z. Imaging Mass Spectrometry of the Visual System: Advancing the Molecular Understanding of Retina Degenerations. PROTEOMICS - Clin. Appl. 2016, $10 \quad$ (4), 391-402. https://doi.org/10.1002/prca.201500103.

(54) Cox, J.; Mann, M. MaxQuant Enables High Peptide Identification Rates, Individualized p.p.b.-Range Mass Accuracies and Proteome-Wide Protein Quantification. Nat. Biotechnol. 2008, 26
Thiede, B.; Höhenwarter, W.; Krah, A.; Mattow, J.; Schmid, M.; Schmidt, F.; Jungblut, P. R. Peptide Mass Fingerprinting. Methods 2005, $35 \quad$ (3 SPEC.ISS.), 237-247. https://doi.org/10.1016/j.ymeth.2004.08.015.

(56) Kyte, J.; Doolittle, R. F. A Simple Method for Displaying the Hydropathic Character of a Protein. J. Mol. Biol. 1982, 157 (1), 105-132. https://doi.org/10.1016/0022-2836(82)90515-0.

Hanley, L.; Wickramasinghe, R.; Yung, Y. P. Laser Desorption Combined with Laser Postionization for Mass Spectrometry. Annu. Rev. Anal. Chem. 2019, 12 (1), annurev-anchem-061318115447. https://doi.org/10.1146/annurev-anchem-061318115447 .

(58) Potthoff, A.; Dreisewerd, K.; Soltwisch, J. Detailed Characterization of the Postionization Efficiencies in MALDI-2 as a Function of Relevant Input Parameters. J. Am. Soc. Mass Spectrom. $\quad \mathbf{2 0 2 0}, \quad 31 \quad$ (9), $1844-1853$. https://doi.org/10.1021/jasms.0c00072.

(59) Lim, H.; Eng, J.; Yates, J. R.; Tollaksen, S. L.; Giometti, C. S.; Holden, J. F.; Adams, M. W. W.; Reich, C. I.; Olsen, G. J.; Hays, L. G. Identification of 2D-Gel Proteins: A Comparison of MALDI/TOF Peptide Mass Mapping to $\mu$ LC-ESI Tandem Mass Spectrometry. J. Am. Soc. Mass Spectrom. 2003, 14 (9), 957-970. https://doi.org/10.1016/S1044-0305(03)00144-2.

(60) Person, M. D.; Lo, H. H.; Towndrow, K. M.; Jia, Z.; Monks, T. J.; Lau, S. S. Comparative Identification of Prostanoid Inducible Proteins by LC-ESI-MS/MS and MALDI-TOF Mass Spectrometry. Chem. Res. Toxicol. 2003, 16 (6), 757-767. https://doi.org/10.1021/tx020049d.

(61) Wettersten, H. I.; Hakimi, A. A.; Morin, D.; Bianchi, C.; Johnstone, M. E.; Donohoe, D. R.; Trott, J. F.; Abu Aboud, O.; Stirdivant, S.; Neri, B.; et al. Grade-Dependent Metabolic Reprogramming in Kidney Cancer Revealed by Combined Proteomics and Metabolomics Analysis. Cancer Res. 2015, 75 (12), 2541-2552. https://doi.org/10.1158/0008-5472.CAN-141703.

(62) Liu, S.; Sun, Y.; Jiang, M.; Li, Y.; Tian, Y.; Xue, W.; Ding, N.; Sun, Y.; Cheng, C.; Li, J.; et al. Glyceraldehyde-3-Phosphate Dehydrogenase Promotes Liver Tumorigenesis by Modulating Phosphoglycerate Dehydrogenase. Hepatology 2017, 66 (2), 631-645. https://doi.org/10.1002/hep.29202.

(63) Tarrado-Castellarnau, M.; Diaz-Moralli, S.; Polat, I. H.; SanzPamplona, R.; Alenda, C.; Moreno, V.; Castells, A.; Cascante, M. Glyceraldehyde-3-Phosphate Dehydrogenase Is Overexpressed in Colorectal Cancer Onset. Transl. Med. Commun. 2017, 2 (1), 6. https://doi.org/10.1186/s41231-017-0015-7.

(64) Gao, J.; Zhao, R.; Xue, Y.; Niu, Z.; Cui, K.; Yu, F.; Zhang, B.; $\mathrm{Li}, \mathrm{S}$. Role of Enolase-1 in Response to Hypoxia in Breast Cancer: Exploring the Mechanisms of Action. Oncol. Rep. 2013, 29 (4), 1322-1332. https://doi.org/10.3892/or.2013.2269.

Zhu, X.; Miao, X.; Wu, Y.; Li, C.; Guo, Y.; Liu, Y.; Chen, Y.; Lu, X.; Wang, Y.; He, S. ENO1 Promotes Tumor Proliferation and Cell Adhesion Mediated Drug Resistance (CAM-DR) in Non-Hodgkin's Lymphomas. Exp. Cell Res. 2015, 335 (2), 216223. https://doi.org/10.1016/j.yexcr.2015.05.020. 

Clinical Value of Peroxiredoxin-1 in Patients with Pancreatic Cancer. Eur. J. Surg. Oncol. 2015, 41 (2), 228-235. https://doi.org/10.1016/j.ejso.2014.11.037.

(67) Kim, J. H.; Bogner, P. N.; Baek, S. H.; Ramnath, N.; Liang, P.; Kim, H. R.; Andrews, C.; Park, Y. M. Up-Regulation of Peroxiredoxin 1 in Lung Cancer and Its Implication as a Prognostic and Therapeutic Target. Clin. Cancer Res. 2008, 14 (8), 2326-2333. https://doi.org/10.1158/1078-0432.CCR-074457.

(68) Sun, S.; Liang, X.; Zhang, X.; Liu, T.; Shi, Q.; Song, Y.; Jiang, Y.; Wu, H.; Jiang, Y.; Lu, X.; et al. Phosphoglycerate Kinase-1 Is a Predictor of Poor Survival and a Novel Prognostic Biomarker of Chemoresistance to Paclitaxel Treatment in Breast Cancer. Br. $\begin{array}{lllll}J . & \text { Cancer } & \mathbf{2 0 1 5}, & 112 & \text { (8), }\end{array}$ https://doi.org/10.1038/bjc.2015.114. 